\title{
Physicochemical Properties of Phosphate Pregelatinized Musa balbisiana Starch as Pharmaceutical Excipient
}

\author{
Deni Anggraini, Anita Lukman, Hilwan Y. Teruna
}

\begin{abstract}
Riau School of Pharmacy (Sekolah Tinggi Farmasi Riau), Pekanbaru, Riau, Indonesia
\end{abstract}
\begin{abstract}
Starch is among the important pharmaceutical excipient, which is particularly used as filler in the tablet formulation and suspending agent. Starch from natural source has a potential to be developed as pharmaceutical excipient with comparable characteristics, including starch from Musa balbisiana (M. balbisiana). This study aimed to synthesize and evaluate physicochemical properties of phosphate pregelatinized M. balbisiana starch. We isolated the starch from M. balbisiana and performed pregelatinization. Since pregelatinized starch still could experience retrogradation which cause syneresis, chemical modification of pre-gelatinized starch was conducted using 5\% of sodium tripolyphosphate at $\mathrm{pH}$ of 9-10. Physicochemical properties of phosphate pregelatinized starch were then investigated. It included the assessment of its organoleptic, $\mathrm{pH}$, water content, particle size distribution, angle of repose, swelling power, amylose content, adsorbs isotherm, and particle analysis using Scanning Electron Microscope (SEM). Phosphate-pregelatinized M. balbisiana starch had low swelling power, better flow properties and viscosity. It can be used particularly in the formulation of slowreleased tablets and suspending agents in suspension formula.
\end{abstract}

Keywords: pregelatinized starch, Musa balbisiana, psychochemical properties, excipients

\section{Introduction}

Starch has crucial roles in pharmaceutical industries. It can be used as filler and binder of the tablets and suspending agent in suspensions. ${ }^{1,2}$ Starch can be found in many parts of the plants, including stem, seed, tuber, and fruit. Banana, Musa balbisiana (M. Balbisiana) contains high concentration of starch. Particularly, starch from kepok banana, which has brighter color than the other types of banana starch, is considered has the best quality. It has $22.81 \%$ of amylose and $77.19 \%$ of amylopectin. ${ }^{3,4}$
Starch can be classified as native and modified starch. Native starch has several weaknesses, including low compressibility, low flow rate, and can not be dissolved in cold water. ${ }^{5}$ Therefore, the modification should be conducted to solve these problems. Starch modification can be done physically, chemically or both. Physical modification can result in pregelatinized starch. It can be conducted by heating the starch with water until gelatinized, then drying it back. Pregelatinized starch has better flow rate and swelling power. ${ }^{2}$

Corresponding author: Deni Anggraini, Riau School of Pharmacy, Pekanbaru, Riau, Indonesia. Email: apt_deni@yahoo.com Received: 28 October 2016. Revised: 23 November 2016. Published: 1 December 2016. 
However, pregelatinized starch has disadvantage, i.e., it can easily retrograded. Retrogradation is crystallization of starch that is already gelatinized. When it is to be used as drug excipients in suspension, it can decrease the homogeneity and stability of liquid. Chemical modification through cross-linking method should be conducted to prevent retrogradation. Previous study showed that this modification can prevent retrogradation in pregelatinized starch from cassava (Manihot esculenta). The product was used in the formulation of dry syrup suspension of amoxicillin. ${ }^{5,6}$

Cross-linking chemical modification can be performed by adding cross-linking agent than can cause new bonds within starch molecules e.g., phosphate. Food-grade phospate includes phosphorus oxychloride and tripolyphosphate sodium. This process can result in better quality of starch, e.g., stronger starch bonds, more resistant to heat, acid, and retrogradation, and better swelling power and stability because of the bond between starch and phosphate or cross linking between hydroxyl functional group. ${ }^{7-9}$

This study was aimed to synthesize phosphate pregelatinized M. Balbisiana starch with cross-linking method and to evaluate its physicochemical properties.

\section{Methods}

Instruments used included mesh (No. 70 and 80), UV spectrometer (Shimadzuß), Enslin tool, scanning electron microscope (SEM), stormer-type viscometer. Materials used included $M$. balbisiana, destilled water, ethanol $95 \%, \mathrm{NaOH}$, tripolyphosphate sodium, $\mathrm{HCl} 1 \mathrm{~N}$, acetic acid $1 \mathrm{~N}$, iodine $2 \%$, $\mathrm{H}_{2} \mathrm{SO}_{4}$ and glycerin.

\section{Starch isolation}

M. Balbisiana aged 80-90 days were cut and soaked in water. It was then mashed and added water $1: 1$, if needed. The pulp was then filtered with flannel. This step was replicated until clarity. Filtrate was dried in the oven at $50^{\circ} \mathrm{C}$ for 24 hours. Dried starch was grinded then filtered with mesh sieve (No. 80). It was then stored at air tight container.

\section{Pregelatinization of starch}

Starch water suspension was made with concentration $5 \% \mathrm{w} / \mathrm{v}$. It was heated on the waterbath below gelatinization temperature $\left(61.55^{\circ} \mathrm{C}\right)$ for 5 minutes. It was then cooled. Starch filtrate was separated and dried in the oven at $50^{\circ} \mathrm{C}$ for 24 hours and filtered with mesh (No. 70).

\section{Phosphate pregelatinized starch}

Pregelatinized starch 15\% (w/w) was added with $\mathrm{NaOH}(20 \% \mathrm{w} / \mathrm{w})$ to $\mathrm{pH} 9-10$. Sodium trypolyphosphate $(5 \% \mathrm{w} / \mathrm{w})$ was made and mixed with pregelatinized solvent. $\mathrm{pH}$ was kept in range of 9-10 using $\mathrm{NaOH} 0.1 \mathrm{~N}$. Reaction was performed until 2 hours with homogenizer at $200 \mathrm{rpm}$. It was neutralized with $\mathrm{HCl} 1 \mathrm{~N}$ to $\mathrm{pH} 7$. It was then cooled in the refrigerator for 12 hours. The mixture was dried in the oven at $50^{\circ} \mathrm{C}$ and filtered with mesh (No. 70).

\section{Starch evaluation}

Phosphate pregelatinized starch was assessed using the following criteria: rendement, organoleptic, solubility, $\mathrm{pH}$, water content, ash content, swelling power, amylose content, isotherm adsorption, water absorption power, particle size distribution, resting angle, viscocity, and syneresis.

\section{Results and Discussion}

Starch formulation with crosslink method was performed. Before addition of sodium trypolyphospate, $\mathrm{pH}$ of starch was set to be 9 with the addition of $\mathrm{NaOH} 20 \%$ w/v. It was conducted because the crosslink bond occurrs 
at the condition $\mathrm{pH}>9 .{ }^{10}$

The weight of our pregelatinized starch and phosphate-pregelatinized starch were $76.71 \%$ and $91.59 \%$, respectively. No difference in organoleptic properties between both types of starches observed. They were in the form of fine white powder, odorless and tasteless. This characteristics still represents the characteristics of starch in general. There was no difference in the solubility of both type of starches. Both starches are insoluble in water and in ethanol $96 \%$.

Starch consists of amylose and amylopectin which can be separated by hot water. Dissolved fraction is amylose and insoluble fraction is amylopectin. Phosphate-pregelatinized starch has higher yield compared to pregelatinized starch. This was caused by heating process, resulting in more molecule of amyloses were dissolved. Starch is a substance that is not soluble in water but can expands. This is because the starch consists of amylose and amylopectin which have different physical properties where amylose is more soluble in water and amylopectin is not soluble in water but expands. ${ }^{11}$

There is a difference in the $\mathrm{pH}$ of both starches. Pregelatinized starch has a $\mathrm{pH}$ of 6.27 whereas phosphate pregelatinized starch has a $\mathrm{pH}$ of 6.96. The $\mathrm{pH}$ of pregelatinized starch was lower because phosphate-pregelatinized starch was affected by the addition of sodium tripolyphosphate which has the $\mathrm{pH}$ of 9.8 and binds to starch molecule. The $\mathrm{pH}$ of both starch still meets the requirements specified in USP XXX edition. The standard $\mathrm{pH}$ for pregelatinized starch is in the range of 4.5-7, while for modified pregelatinized starch should be in the $\mathrm{pH}$ of 3-9. Phosphate pregelatinized starch has a more neutral $\mathrm{pH}$ than pregelatinized starch. ${ }^{12}$
Pregelatinized starch had a moisture content of $11.73 \%$ while phosphate pregelatinized starch has moisture content of $11.98 \%$. Both starch still meet the requirements stated in Handbook of Pharmaceutical Excipients $(<14 \%)$. Higher moisture content in phosphate pregelatinized starch depicts its ability to trap water strongly due to the addition of phosphates which play a key role in strengthening hydrogen starch bonds. ${ }^{11}$ However, moisture content can affect starch stability during storage because high water content can be a good medium for microbial growth which can decrease stability and quality of starch. ${ }^{13}$

Pregelatinized and phosphate pregelatinized starch had ash content of $0.21 \%$ and $0.44 \%$, respectively. The ash content of both starch still meet the requirements contained in Indonesian Pharmacopoeia (1995) which should not exceed $0.6 \%$. Most starch $(96 \%)$ consist of organic materials and water, the rest are mineral elements. Mineral elements are also known as inorganic substances or ash. In the process of burning, organic materials was burnt, but inorganic substances are not because of ash content. From the two type starches, ash content in phosphate pregelatinized starch was higher because it has a crosslink bond between starch molecules and the addition of phosphate compound which is an inorganic substance. ${ }^{12}$

Regarding swelling power, pregelatinized starch could swell into $150 \%$ while phosphate pregelatinized starch only $15.59 \%$. This was because pregelatinized starch has swollen starch granules which can cause water hydroxyl group to bind with more starch and high amylopectin content which can increase starch expansion/swelling power. ${ }^{8}$

Phosphate pregelatinized starch has higher amylopectin content but the starch swelling 


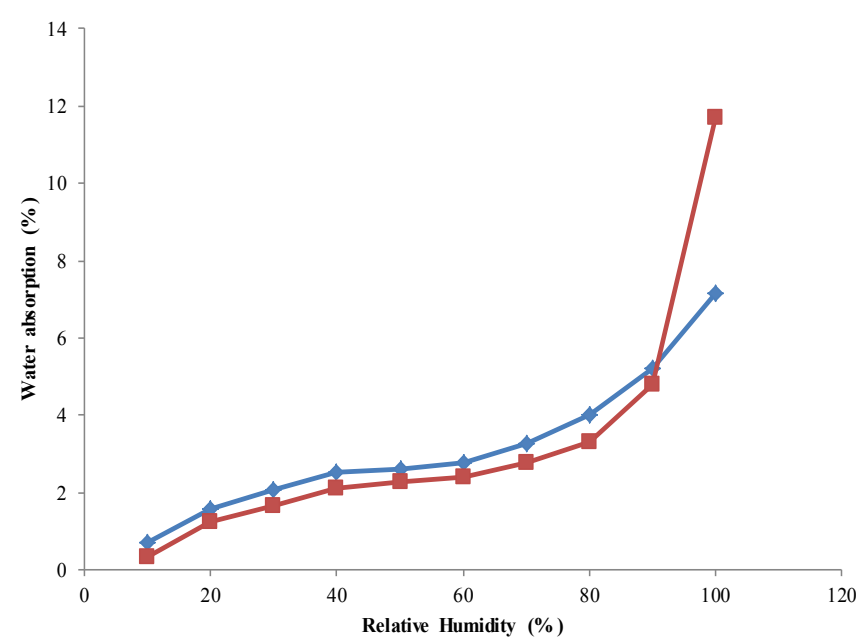

Figure 1. Isoterm adsorption curve of pregelatinized starch and phosphate pregelatinized starch of M. balbisiana.

ability is lower because of crosslinking which can block the starch expansion. Crosslink bonding can limit water penetration and strengthen hydrogen bonds between polymer chains in starch to make starch difficult to expand. The low swelling power of phosphate pregelatinized can be utilized for slow drug delivery, as the lower the swelling of the starch, the longer the tablets will be destroyed.

Level of amylose in pregelatinized starch was $21.54 \%$ and in phosphate pregelatinized starch was $16.58 \%$. This was because the amylose in phosphate pregelatinized starch was hydrolyzed by acid and base solution which was added.

Evaluation of water absorption using Water absorption ability of pregelatinized starch and phosphate-pregelatinized starch were $1.15 \mathrm{ml} / \mathrm{mg}$ and $0.9 \mathrm{ml} / \mathrm{mg}$, respectively. The differences in the ability to absorb water is influenced by the amount of hydroxyl groups in the amylose molecules that can bind water molecules. Phosphate pregelatinized starch has lower amylose content which affect its ability to absorb water. Moreover, the addition of sodium tripolyphosphate causes the hydroxyl group in starch to bind to the phosphate group, so that the ability of this starch to be able to bind with water becomes lower. ${ }^{14,15}$

The results of observation of starch granules using SEM showed a difference between both type of starches. There were broken starch granules in pregelatinized starch whereas phosphate pregelatinized starch did not show any broken starch granules. This was because the pre-gelatinized starch experienced gelatination resulting in broken starch granules, while in phosphate pregelatinized starch, the rupture in starch granules allows the water to enter so that the granules are hydrolyzed and dissolved during the formulation. This process resulted in no broken starch granules were found.

There were no differences in the shape of starch granules because the chemical modification of starch did not change the granular shape. Differences between these starches could be seen from the black spot on the surface of phosphate pregelatinized starch, where the black zone is formed due 


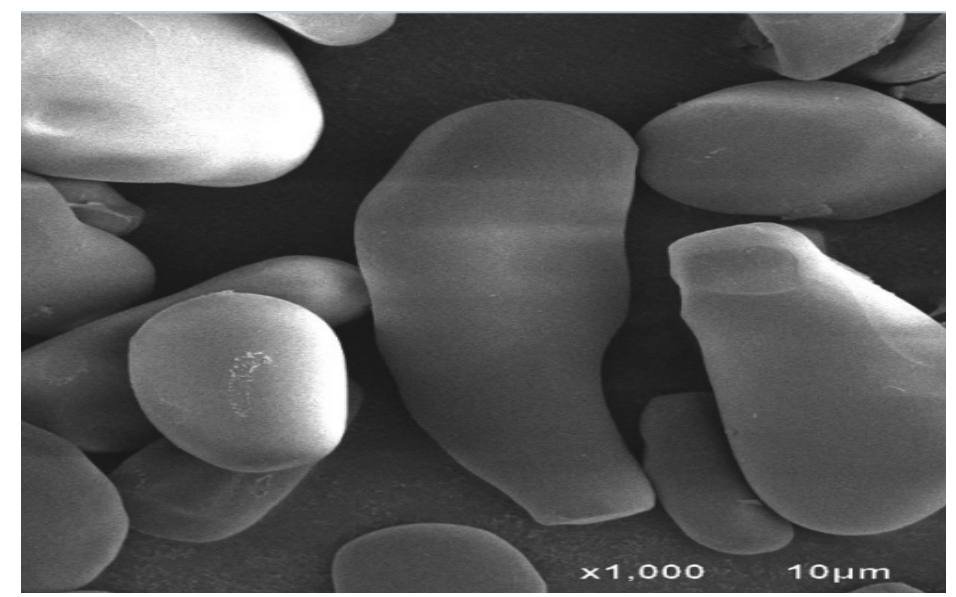

Figure 2. Pregelatinized M. balbisiana starch (Magnification:1000x)

to the influence of crosslinking starch with sodium tripolyphosphate.

Evaluation of particle size distribution using vibrational sieve showed that mean diameter of pregelatinized starch was $116.99 \mu \mathrm{m}$ and phosphate pregelatinized starch was 123.80 $\mu \mathrm{m}$. The evaluation of this particle size distribution aims to determine the range of particle size and distribution, where the particle size affects the flow properties and uniformity of the excipient in drugs dosage from. It will ultimately affect drug therapy. Larger particle size has a lower cohesiveness resulting in better flow properties. Phosphate pregelatinized starch were greater in the particle size, so that this starch had better flow properties..$^{13-15}$

Regarding evaluation of the lift angle, pregelatinized starch has a lift value of $31.01^{\circ}$ and $23.01^{\circ}$ for phosphate pregelatinized starch. The resting angle in theory reflects the flow properties of a powder. If the resting angle is smaller or equal to $30^{\circ}$ it usually indicates that the material can flow freely, when the angle is greater than or equal to $40^{\circ}$ the flow ability is not sufficient. From these results, it can

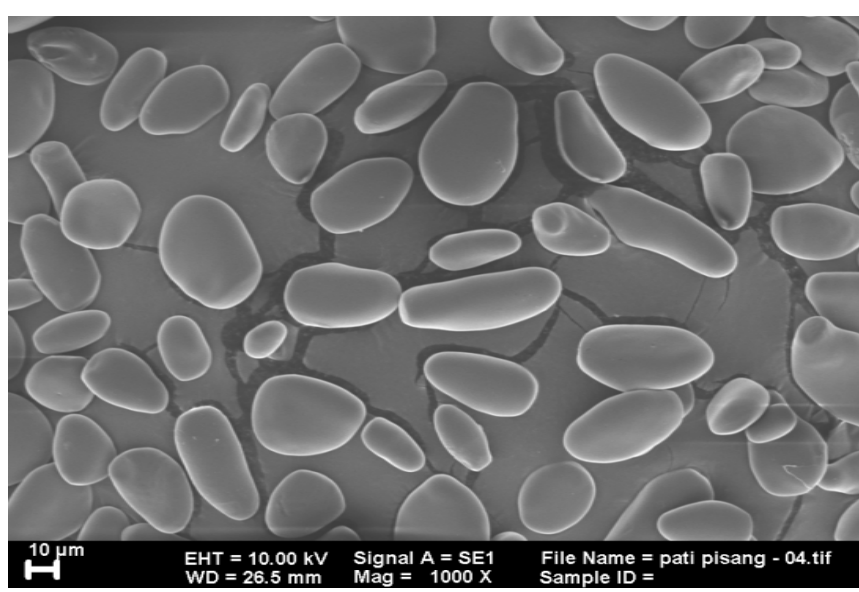

Figure 3. Phosphate pregelatinized M. balbisiana starch (Magnification:1000x) 
be concluded that phosphate-pregelatinized starch has better flow properties than pregelatinized starch. ${ }^{16}$

The viscosity evaluation was made with $5 \%$ starch dispersion concentration. The viscosity tests were performed for 7 days on days 1 and 7 to see stability of starch during the storage. The results showed that phosphate pregelatinized starch has a higher viscosity than that of pregelatinized starch, but both starches experienced declining in viscosity on day 7. Phosphate pregelatinized starch had a viscosity which was more stable than pregelatinized starch, because of the presence of crosslink. Excessive viscosity can disrupts the redispersion system. ${ }^{13}$ However, too low viscosity can disrupt the homogeneity of the mixture which would interfere with the doses. Overall, phosphate-pregelatinized starch has the potential to be used as the suspension material.

The observation of syneresis assessed the physical change of starch dispersion. It can be influenced by the concentration of starch, temperature, the presence of other compounds and the length of storage time of starch dispersion. At this observation the starch dispersion is made in different concentrations and temperature treatments. Syneresis observations were performed with various concentrations (5\% and $10 \%$ for 14 days and each concentration was placed at room temperature and temperature of the refrigerator). At the concentration of 5\% and $10 \%$ in room temperature, phosphatepregelatinized starch has longer experience of syneresis.

The data showed that phosphate pregelatinized starch dispersion is more stable than pregelatinized starch dispersion, because phosphate pregelatinized starch has a crosslink bond that is able to bind water stronger so more stable gel could be formed. On the second day, pregelatinized starch dispersion showed an instability characterized by odor discharge on starch dispersion, whereas phosphate pregelatinized starch dispersion has no odor until day 14 , due to phosphate bonds between starch and sodium tripolyphosphate which also have preservative properties.

\section{Conclusion}

Overall, phosphate pregelatinized showed better results compared to pregelatinized one. Physical and chemical modification of $M$. balbisiana pregelatinized starch by crosslink method could result in lower swelling power and better flow properties and viscosity. The phosphate pregelatinized starch can be used in the formulation of slow release tablets and suspending agents in suspension formula.

\section{References}

1. Manek RV, Builders PF, Kolling WM, et al. Physicochemical and binder properties of starch obtained from Cyperus esculentus. Pharmaceutical Sciences and Technology. 2012;13(2):379-388.

2. Mimura K, Kanada K, Uchida S, et al. Formulation study for orally disintegrating tablet using partly pregelatinized starch binder. Chemical Pharmacy Bulletin. 2011; 59: 959-964.

3. Haslinda WH, Cheng LH, Chong $\mathrm{C}$, et al. Chemical composition and physicochemical properties of green banana (Musa acuminata) flour. International Journal of Food Science and Nutrition. 2009;60(Suppl 4):S232-9.

4. Ramli SB, Alkarkhi AFM, Yong YS, et al. The use of principle component and cluster analyses to differentiate banana pulp flours based on starch and dietary fibre components. International Journal of Food Science and Nutrition. 2009;60:317-25. 
5. Anwar E, Anthokalina H. Phospate modified cassava starch for the excipient in amphycillin dry suspension. Pharmaceutical Sciences Journal. 2006;2(3):117-126.

6. Anwar E, Khotimah H, Yanuar A. An approach on pregelatinized cassava starch phosphate esters as hydrophilic polymer excipient for controlled release tablet. Journal of Medical Science. 2010;6(6):923-929.

7. Carmona GR, Sanchez RM, Mendez $\mathrm{MG}$, et al. Effect of the cross-linked reagent type on some morphological, physicochemical and functional characteristics of banana starch (Musa paradisiaca). Carbohydrate Polymers. 2009;76: 117-122.

8. Kalsum N. Characteristics of dextrin from sweet potato starch synthesized using partial pregelatinization. Journal of Applied Agrotechnology Research. 2010;13(1):13-23.

9. Ritte G, Heydenreich M, Mahlow S, et al. Phosphorylation of C6 and C3-position of glucosyl residues in starch. FEBS Letters. 2006;560:4872-4876

10. Zhang X, Do MD, Casey P, et al Chemical cross-linking gelatin with natural phenolic compounds as studied by high-resolution NMR spectroscopy. Biomacromolecules. 2010;11(4):1125-1132.

11. Nunes FM, Lopes ES, Moreira AS. Formation of type 4 resistant starch and maltodextrins from amylose and amylopectin upon dry heating: a model study. Carbohydrate Polymers. 2016;5(141):253-262.

12. United States Pharmacopeia. 2007. United States: USP Convention

13. Shah RB, Tawakkul MA, Khan MA. Comparative evaluation of flow for pharmaceutical powders and granules. Pharmaceutical Science and Technology. 2008;9(1):250-258.

14. Morin G, Briens L. The effect of lubricants on powder flowability for pharmaceutical application. Pharmaceutical Science and Technology. 2013;14(3):1158-1168.

15. Yoon SD. Cross-linked potato starchbased blend films using ascorbic acid as plasticizer. Journal of Agricultural and Food Chemistry. 2014;62(8):1755-1764.

16. Wang T, Wang X, LuoZ, et al. Mechanisms of viscocity increase for nanocolloidal dispersions. Journal of Nanoscience and Nanotechnology. 2011;11(4):3141-3150. 